\title{
Close association of water channel AQP1 with amyloid- $\beta$ deposition in Alzheimer disease brains
}

\author{
Tamako Misawa $\cdot$ Kunimasa Arima $\cdot$ \\ Hidehiro Mizusawa $\cdot$ Jun-ichi Satoh
}

Received: 10 March 2008 / Revised: 5 May 2008 / Accepted: 5 May 2008 / Published online: 29 May 2008

(C) The Author(s) 2008

\begin{abstract}
Aquaporin-1 (AQP1), a membrane water channel protein, is expressed exclusively in the choroid plexus epithelium in the central nervous system under physiological conditions. However, AQP1 expression is enhanced in reactive astrocytes, accumulating in brain lesions of Creutzfeldt-Jakob disease and multiple sclerosis, suggesting a role of AQP1-expressing astrocytes in brain water homeostasis under pathological conditions. To clarify a pathological implication of AQP1 in Alzheimer disease (AD), we investigated the possible relationship between amyloid-beta $(\mathrm{A} \beta)$ deposition and astrocytic AQP1 expression in the motor cortex and hippocampus of $11 \mathrm{AD}$ patients and 16 age-matched other neurological disease cases. In all cases, AQP1 was expressed exclusively in a subpopulation of multipolar fibrillary astrocytes. The great majority of
\end{abstract}

Electronic supplementary material The online version of this article (doi:10.1007/s00401-008-0387-x) contains supplementary material, which is available to authorized users.

T. Misawa $\cdot$ J. Satoh $(\bowtie)$

Department of Bioinformatics and Molecular Neuropathology, Meiji Pharmaceutical University, 2-522-1 Noshio,

Kiyose, Tokyo 204-8588, Japan

e-mail: satoj@my-pharm.ac.jp

K. Arima

Department of Laboratory Medicine, National Center Hospital, National Center of Neurology and Psychiatry, Tokyo, Japan

T. Misawa $\cdot$ H. Mizusawa

Department of Neurology and Neurological Sciences,

Tokyo Medical and Dental University, Tokyo, Japan

J. Satoh

Department of Immunology, National Institute of Neuroscience, National Center of Neurology and Psychiatry, Tokyo, Japan
AQP1-expressing astrocytes were located either on the top of or in close proximity to $\mathrm{A} \beta$ plaques in $\mathrm{AD}$ brains but not in non- $\mathrm{AD}$ cases, whereas those independent of $\mathrm{A} \beta$ deposition were found predominantly in non-AD brains. By Western blot, cultured human astrocytes constitutively expressed $\mathrm{AQP} 1$, and the levels of $\mathrm{AQP} 1$ protein expression were not affected by exposure to $\mathrm{A} \beta_{1-42}$ peptide, but were elevated by hypertonic sodium chloride. By immunoprecipitation, the C-terminal fragment-beta $(\mathrm{CTF} \beta)$ of amyloid precursor protein interacted with the N-terminal half of AQP1 spanning the transmembrane helices $\mathrm{H} 1, \mathrm{H} 2$ and $\mathrm{H} 3$. These observations suggest the possible association of astrocytic $\mathrm{AQP} 1$ with $\mathrm{A} \beta$ deposition in $\mathrm{AD}$ brains.

Keywords Alzheimer disease (AD) - Amyloid-beta (A $\beta)$. Aquaporin-1 (AQP1) · Astrocytes · Water homeostasis

\section{Introduction}

The aquaporins (AQPs) constitute a family of integral channel proteins that facilitate the osmotically driven bidirectional water transport across the cell membrane [2, 54]. Previous studies identified at least 13 mammalian members, widely expressed in various fluid-transporting epithelial and endothelial cells. AQP1, AQP2, AQP4, AQP5 and AQP8 are chiefly water selective, while AQP3, AQP7, $\mathrm{AQP} 9$ and AQP10 transport glycerol in addition to water. Among AQP family members, AQP1, AQP4 and AQP9 are expressed in the central nervous system (CNS) [2, 54]. AQP1, initially identified in red blood cells and renal proximal tubular epithelium, is expressed constitutively in the apical surface of choroid plexus epithelium in the CNS [8, 39]. The crystal structure of AQP1 water channel is composed of a dumbbell-shaped homotetramer of $28-\mathrm{kDa}$ 
subunits, each of which contains six transmembrane domains and an extracellular epitope that defines the Colton blood group antigen on erythrocyte membranes [10]. Outside the brain, AQP1 is expressed in retinal amacrine cells [24], Schwann cells [14], dorsal root ganglia neurons [48], lungs and hepatobiliary epithelium. AQP1-null individuals negative for the Colton antigen, having homozygous mutations in the AQP1 gene exhibit a defect in urinary concentration and reduced pulmonary vascular permeability after overloading fluid [27, 28]. AQP1-null mice show a decrease in cerebrospinal fluid (CSF) production, indicating a pivotal role of AQP1 in CSF secretion in the CNS [42]. Although AQP1 is expressed widely in vascular endothelial cells outside the CNS, the levels of AQP1 expression are very low in brain endothelial cells, and no expression is found in cultured rodent astrocytes [12].

Earlier studies showed that high-grade astrocytoma cells intensely express both AQP1 and AQP4, suggesting the involvement of water channel upregulation in development of tumor-associated brain edema [41, 45]. AQP1-null mice show a reduction in tumor vascularity and migratory capacity [46]. In contrast, overexpression of AQP1 in fibroblast in culture accelerates anchorage-independent cell growth characteristic of malignant transformation [19]. Mouse melanoma cells, overexpressing AQP1 show an increase in metastatic potential [21]. AQP1 plays a central role in macrophage and leukocyte recruitment during acute inflammation [40]. Based on these observations, it is proposed that AQP1 regulates cell growth and migration by a mechanism that involves cytoskeletal reorganization, triggered by water transport at the leading edge of proliferating and migrating cells [54]. Furthermore, AQP1 plays a role in apoptotic cell shrinkage by regulating the cell volume [22].

Increasing evidence indicates that astrocytes express AQP1 in CNS under pathological conditions. The expression of both AQP1 and AQP4 is enhanced markedly in reactive astrocytes accumulating in the lesions of subarachnoid hemorrhage [4], contusion [51], Creutzfeldt-Jakob disease (CJD) [44], cerebral infarction [47], and multiple sclerosis (MS) [47]. However, the precise mechanism accounting for upregulation of AQP1 in reactive astrocytes remains unknown. A recent study showed that the expression of AQP1 but not that of AQP4 is augmented in cortical astrocytes at the early stage of Alzheimer disease (AD), suggesting a pathological role of abnormal regulation of water transport in $\mathrm{AD}$ [43]. Because intracerebral accumulation of amyloid- $\beta$ (A $\beta$ ) plays a central role in the pathogenesis of $\mathrm{AD} \mathrm{[16],} \mathrm{and} \mathrm{activated} \mathrm{astrocytes} \mathrm{are} \mathrm{often}$ associated with $\mathrm{A} \beta$ plaques in $\mathrm{AD}$ brains $[37,55]$, we investigated the possible relationship between $\mathrm{A} \beta$ deposition and AQP1 expression in astrocytes in the cerebral cortex of AD.

\section{Materials and methods}

Human brain tissues

Ten micron-thick serial sections were prepared from autopsied brains of 11 AD patients composed of five men and six women with the mean age of $71 \pm 9$ years and 16 other neurological disease (non-AD) patients composed of nine men and seven women with the mean age of $67 \pm 12$ years. The non-AD cases include three patients with Parkinson disease (PD), three with multiple system atrophy (MSA), four with amyotrophic lateral sclerosis (ALS), three with myotonic dystrophy, one with spinal and bulbar muscular atrophy (SBMA), one with schizophrenia, and one with mitochondrial myopathy, encephalopathy, lactic acidosis, and stroke-like episodes (MELAS). The average of brain weight was $1,038 \pm 163 \mathrm{~g}$ in $\mathrm{AD}$ cases and 1,220 $\pm 173 \mathrm{~g}$ in non-AD cases. Brain tissues of the motor cortex and hippocampus were fixed with $4 \%$ paraformaldehyde (PFA) and embedded in paraffin. In the present study, we tentatively defined the hippocampus and parahippocampal cortex as the hippocampus. All AD cases were satisfied with the Consortium to Establish a Registry for Alzheimer's disease (CERAD) criteria for diagnosis of definite AD [34]. They were categorized into stage $\mathrm{C}$ of amyloid deposition and stage VI of neurofibrillary degeneration, following the Braak's staging [9]. The autopsied brain samples were obtained from Research Resource Network (RRN), Japan. Written informed consent was obtained from all the cases examined. The Ethics Committee of National Center of Neurology and Psychiatry approved the present study.

Human astrocytes in culture

Human astrocytes were established from neuronal progenitor (NP) cells isolated from a human fetal brain (BioWhittaker-Cambrex, Walkersville, MD, USA). NP cells plated on a polyethyleneimine-coated surface were incubated in DMEM/F-12 medium (Invitrogen, Carlsbad, CA, USA) containing an insulin-transferrin-selenium (ITS) supplement (Invitrogen), $20 \mathrm{ng} / \mathrm{ml}$ recombinant human EGF (Higeta, Tokyo, Japan), $20 \mathrm{ng} / \mathrm{ml}$ recombinant human bFGF (PeproTech EC, London, UK), and $10 \mathrm{ng} / \mathrm{ml}$ recombinant human LIF (Chemicon, Temecula, CA, USA). For the induction of astrocyte differentiation, NP cells were incubated for several weeks in DMEM (Invitrogen) supplemented with $10 \%$ fetal bovine serum (FBS), $100 \mathrm{U} / \mathrm{ml}$ penicillin and $100 \mu \mathrm{g} / \mathrm{ml}$ streptomycin (feeding medium). The inclusion of FBS in the culture medium induced vigorous proliferation and differentiation of astrocytes accompanied by a rapid reduction in non-astroglial cells. The purity of astrocytes exceeded $98 \%$ by GFAP immunolabeling, as described previously [47]. 
To determine the effects of stress-inducing stimuli on AQP1 expression, human astrocytes were incubated for $48 \mathrm{~h}$ in the feeding medium with inclusion of $10 \mu \mathrm{M}$ human $\mathrm{A} \beta_{1-40}$ peptide (Peptide Institute, Osaka, Japan), $10 \mu \mathrm{M}$ human $\mathrm{A} \beta_{1-42}$ peptide (Peptide Institute), $100 \mathrm{mM} \mathrm{NaCl}$, $100 \mu \mathrm{M}$ sodium nitroprusside, a NO donor (SNP; MerckCalbiochem, Tokyo, Japan), $10 \mu \mathrm{M}$ all trans retinoic acid (RA; Sigma, St Louis, MO, USA), $100 \mathrm{nM}$ phorbol 12myristate 13-acetate (PMA; Sigma), $1 \mathrm{mM}$ dibutyryl cyclic AMP (dbcAMP; Sigma), $10 \mu \mathrm{M}$ MG-132, a proteasome inhibitor (Merck-Calbiochem), or $1 \mu \mathrm{M}$ thapsigargin, an endoplasmic reticulum (ER) stress inducer (TG; Sigma), or incubated in the serum-free DMEM/F-12 medium containing $100 \mu \mathrm{M}$ hydrogen peroxide.

\section{Double-labeling immunohistochemistry}

After deparaffination, tissue sections were heated in $10 \mathrm{mM}$ citrate sodium buffer, $\mathrm{pH} 6.0$ by autoclave at $125^{\circ} \mathrm{C}$ for $30 \mathrm{~s}$ in a temperature-controlled pressure chamber (Dako, Tokyo, Japan). For $\mathrm{A} \beta$ immunolabeling, tissue sections were pretreated with formic acid for $5 \mathrm{~min}$ at room temperature (RT). All tissue sections were incubated with phosphate-buffered saline (PBS) containing 10\% normal goat serum (NGS) at RT for $15 \mathrm{~min}$ to block non-specific staining. Then, tissue sections were initially stained at $4^{\circ} \mathrm{C}$ overnight with primary antibodies listed in Table 1, followed by incubation with alkaline phosphatase (AP)-conjugated secondary antibody (Nichirei), and colorized with New Fuchsin substrate. The specificity of anti-AQP1 antibody (H-55, Santa Cruz Biotechnology, Santa Cruz, CA, USA) and anti-AQP4 antibody (H-80, Santa Cruz Biotechnology) was verified by Western blot analysis of HEK293 cells that express the transgene of human AQP1 or AQP4 as described previously [47]. In addition, we found that choroid plexus epithelial cells, representing a positive control cell type, were stained intensely by H-55 (Supplementary Fig. 1). After inactivation of the antibody by autoclaving the sections at $125^{\circ} \mathrm{C}$ for $30 \mathrm{~s}$ in $10 \mathrm{mM}$ citrate sodium buffer, $\mathrm{pH}$ 6.0 following the manufacturer's instruction (Nichirei), they were treated for $15 \mathrm{~min}$ with $3 \%$ hydrogen peroxide-containing distilled water to block the endogenous peroxidase activity. Then, they were relabeled with different primary antibodies listed in Table 1, followed by incubation with horseradish peroxidase (HRP)-conjugated secondary antibody (Nichirei), and colorized with DAB substrate and counterstained with hematoxylin. For negative controls, the step of incubation with primary antibodies was omitted.

In the motor cortex and hippocampus of each case, the number of $\mathrm{A} \beta^{+} \mathrm{AQP} 1^{+}$plaques, $\mathrm{A} \beta^{-} \mathrm{AQP} 1^{+}$spots, and $\mathrm{A} \beta^{+} \mathrm{AQP} 1^{-}$plaques with size exceeding the diameter of $50 \mu \mathrm{m}$ was counted in ten random fields at $400 \times$ microscopic magnification on the Olympus BX51 universal microscope. The average of percentages of $\mathrm{A} \beta^{+} \mathrm{AQP} 1^{+}$ plaques, $\mathrm{A} \beta^{-} \mathrm{AQP} 1^{+}$spots, and $\mathrm{A} \beta^{+} \mathrm{AQP} 1^{-}$plaques, the average of numbers of $\mathrm{A} \beta$-immunoreactive plaques, and the average of numbers of AQP1-immunoreactive plaques/ spots were compared between $\mathrm{AD}$ and non-AD cases by statistical analysis with a Mann-Whitney's $U$ test. The $P$ value of $<0.05$ was considered as significant.

\section{Immunocytochemistry}

For immunocytochemistry, the cells on cover glasses were fixed with $4 \%$ PFA in $0.1 \mathrm{M}$ phosphate buffer, $\mathrm{pH} 7.4$ at RT for $5 \mathrm{~min}$, followed by incubation with PBS containing $0.5 \%$ Triton X-100 at RT for 3 min. After blocking non-specific staining by PBS containing 10\% NGS, the cells were incubated at RT for $30 \mathrm{~min}$ with a mixture of anti-GFAP antibody GA5 and anti-AQP1 antibody H-55. Then, they were incubated at RT for $30 \mathrm{~min}$ with a mixture of Alexa Fluor 568-conjugated anti-mouse $\operatorname{IgG}$ (Invitrogen) and Alexa Fluor 488-conjugated anti-rabbit IgG (Invitrogen). After several washes, they were mounted with an anti-fade reagent containing 4', 6' ${ }^{\prime}$-diamidino-2-phenylindole (DAPI) (Invitrogen), and examined on the Olympus BX51 universal microscope. Negative controls were processed following all the steps, except for exposure to anti-AQP1 antibody.

\section{Western blot analysis}

To prepare total protein extract, the cells were homogenized in RIPA lysis buffer, composed of $50 \mathrm{mM}$ Tris- $\mathrm{HCl}$, pH 7.5, $150 \mathrm{mM} \mathrm{NaCl}, 1 \%$ Nonidet P40, $0.5 \%$ sodium deoxycholate, $0.1 \%$ SDS, and a cocktail of protease inhibitors (Sigma), followed by centrifugation at $12,000 \mathrm{rpm}$ for 10 min at RT. The supernatant was collected, solved in the lysis buffer containing $2.5 \mathrm{M}$ urea, and separated on a $12 \%$ SDS-PAGE gel [47]. The protein concentration was determined by a Bradford assay kit (BioRad, Hercules, CA, USA). After gel electrophoresis, the protein was transferred onto nitrocellulose membranes, and immunolabeled at RT overnight with anti-AQP1 antibody H-55. Then, the membranes were incubated at RT for $30 \mathrm{~min}$ with HRPconjugated anti-rabbit IgG (Santa Cruz Biotechnology). The specific reaction was visualized by exposing to a chemiluminescent substrate (Pierce, Rockford, IL, USA). After the antibodies were stripped by incubating the membranes at $50^{\circ} \mathrm{C}$ for $30 \mathrm{~min}$ in stripping buffer, composed of $62.5 \mathrm{mM}$ Tris- $\mathrm{HCl}, \mathrm{pH}$ 6.7, 2\% SDS and $100 \mathrm{mM}$ 2-mercaptoethanol, the membranes were processed for relabeling with mouse monoclonal anti- $\beta$-actin antibody AC-15 (Sigma).

Immunoprecipitation analysis

To determine the molecular interaction between $\mathrm{A} \beta$ and $\mathrm{AQP} 1$, the N-terminal half of AQP1, including the transmem- 


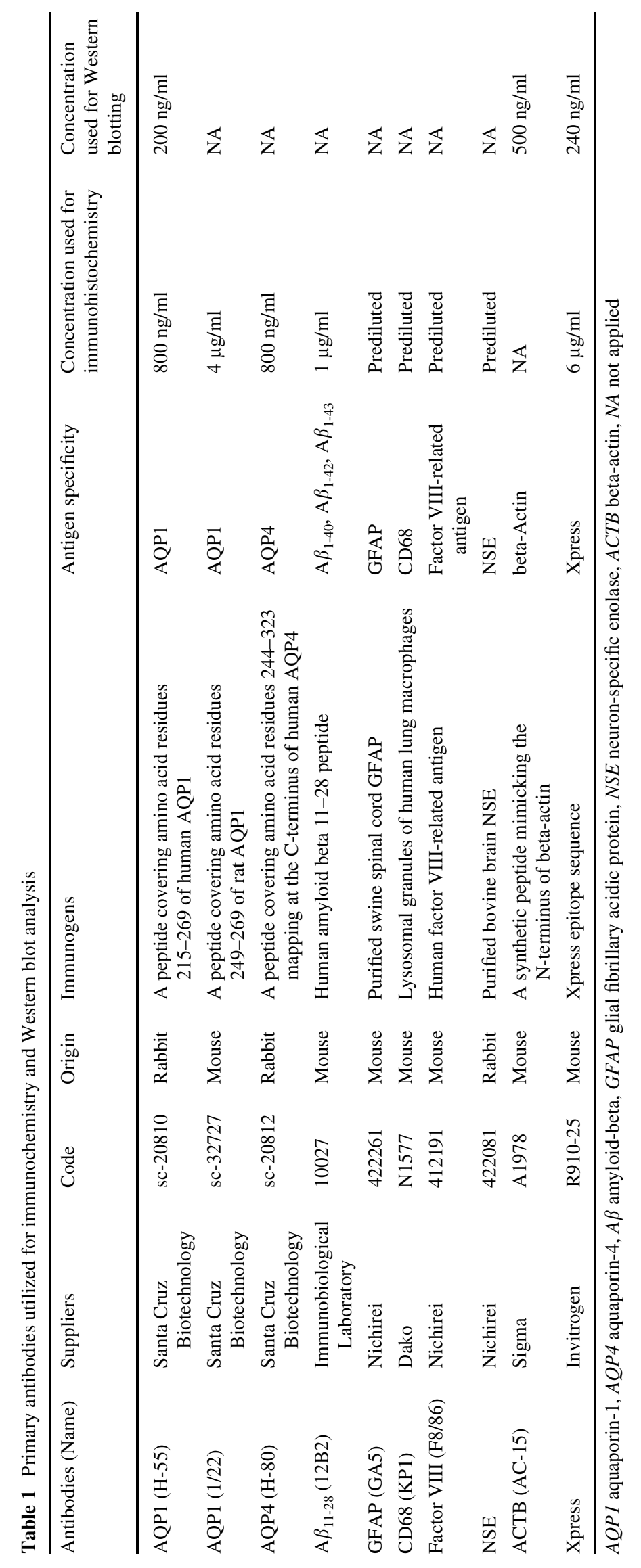


brane helices $\mathrm{H} 1, \mathrm{H} 2$ and $\mathrm{H} 3$ (amino acid residues 2-132; NTF), the C-terminal half of AQP1, including the transmembrane helices H4, H5 and H6 (amino acid residues 133-269; CTF) $[10,32]$ (GenBank accession No. NM_198098), and the C-terminal fragment $\beta$ (amino acid residues 597-695; CTF $\beta$ ) of amyloid precursor protein (APP) (NM_201414) were amplified by PCR using PfuTurbo DNA polymerase (Stratagene, La Jolla, CA, USA) and the sense and antisense primer sets following: $5^{\prime}$ 'ccgaattccggccagcgagttcaagaagaag $3^{\prime}$ and $5^{\prime}$ for the NTF of AQP1, 5' cggaattccggtgaactcgggccagggcct3' and $5^{\prime}$ 'ggggtacccegctatttgggcttcatctccac $3^{\prime}$ for the CTF of $\mathrm{AQP1}$, and 5' and 5'cgggatccegctagttctgcatctgctcaaagaa3' for the CTF $\beta$ of APP. After digestion with EcoRI, KpnI, XbaI or BamHI (New England BioLabs, Beverly, MA, USA), the PCR products were cloned in the expression vectors pCMV-Myc (Clontech, Mountain View, CA, USA) or p3XFLAG-CMV7.1 (Sigma) to express a fusion protein with an N-terminal Flag or Myc tag. At $48 \mathrm{~h}$ after co-transfection of the vectors, HEK293 cells were homogenized in M-PER lysis buffer (Pierce) supplemented with a cocktail of protease inhibitors. After preclearance, the supernatant was incubated at $4^{\circ} \mathrm{C}$ overnight with mouse monoclonal anti-Flag M2 affinity gel (Sigma), rabbit polyclonal anti-Myc antibody-conjugated agarose (Sigma), or the same amount of normal mouse or rabbit IgG-conjugated agarose (Santa Cruz Biotechnology). After several washes, the immunoprecipitates were processed for Western blot with rabbit polyclonal anti-Myc antibody (Sigma) and mouse monoclonal anti-FLAG M2 antibody (Sigma).

\section{Cell imaging analysis}

The open reading frame (ORF) of the genes encoding AQP1 (amino acid residues 2-269) and the CTF $\beta$ or A $\beta_{1-42}$ of APP were amplified by PCR using PfuTurbo DNA polymerase and the sense and antisense primer sets following: $5^{\prime} \mathrm{gcc}$ agcgagttcaagaagaagctc $3^{\prime}$ and $5^{\prime}$ ctatttgggettcatctccaccet 3 'for AQP1, 5' and 5'cgggatccegctagttctgcatctgctcaaagaa3' for the CTF $\beta$ of APP, and 5' cgggatccegctacgctatgacaacaccgcccac $3^{\prime}$ for A $\beta_{1-42}$. After digestion with EcoRI, KpnI, XhoI or BamHI, the PCR products were cloned in the expression vectors pDsRed-Express-C1 (Clontech) or pcDNA3.1/NT/GFP-TOPO (Invitrogen) to express a fusion protein with an $\mathrm{N}$-terminal DsRed or GFP tag. At 24-48 h after co-transfection of the vectors, HEK293 cells were fixed briefly in 4\% PFA and mounted with the anti-fade reagent containing DAPI.

\section{Tissue protein overlay analysis}

To identify AQP1-binding targets in brain tissues in situ, we prepared recombinant human AQP1 protein tagged with Xpress (AQP1-Xpress), serving as a probe for tissue protein overlay. The ORF of AQP1 gene amplified by PCR described above was cloned into a prokaryotic expression vector pTrcHis-TOPO (Invitrogen), expressed in E. coli, and purified to obtain a fusion protein having an $\mathrm{N}$-terminal Xpress tag. After deparaffination, tissue sections were heated in $10 \mathrm{mM}$ citrate sodium buffer, $\mathrm{pH} 6.0$ by autoclave at $125^{\circ} \mathrm{C}$ for $30 \mathrm{~s}$. They were treated with formic acid and $3 \%$ hydrogen peroxide, and then incubated at $4^{\circ} \mathrm{C}$ overnight with AQP1-Xpress at the concentration of $167 \mu \mathrm{g} / \mathrm{ml}$ or with the same amount of recombinant $\beta$-galactosidase fragment tagged with Xpress (LacZ-Xpress), serving as a negative control. After washing with PBS, the tissue sections were incubated at RT for 45 min with anti-Xpress antibody, followed by incubation with HRP-conjugated secondary antibody, and colorized with DAB substrate. After inactivation of the antibodies by autoclaving, the tissue sections were processed for immunolabeling with anti-A $\beta$ antibody, followed by incubation with AP-conjugated secondary antibody, and colorized with New Fuchsin substrate.

\section{Results}

The close association of AQP1-expressing astrocytes with $\mathrm{A} \beta$ deposition in the cerebral cortex of $\mathrm{AD}$

First, we studied AQP1 and AQP4 expression in the motor cortex and hippocampus of $11 \mathrm{AD}$ cases and 16 agematched other neurological disease (non-AD) cases by double-labeling immunohistochemistry with a combination of anti-AQP1 antibody, anti-AQP4 antibody, anti-A $\beta$ antibody, and antibodies against cell type-specific markers. In all cases, examined, AQP1 was expressed exclusively in multipolar fibrillary astrocytes with highly-branched processes that often surround blood vessels and neurons (Figs. 1a, b, d-f, 2a, c-e). Neither $\mathrm{NSE}^{+}$neurons nor $\mathrm{CD}^{+} 8^{+}$microglia nor factor VIII-related antigen-positive vascular endothelial cells were immunolabeled with AQP1 antibody (Figs. 1e, f, 2a). Approximately $70 \%$ of AQP1 ${ }^{+}$ multipolar fibrillary cells coexpressed an intense GFAP immunoreactivity, verifying that they represent a subpopulation of astrocytes with a unique morphology (Fig. 1d). Importantly, AQP1-expressing astrocytes were either often located on the top of or in close proximity to $\mathrm{A} \beta$ plaques in the motor cortex and hippocampus of $\mathrm{AD}$, but rarely in non-AD cases (Fig. 1a).

In contrast, AQP4 immunoreactivity was distributed more diffusely in the whole neuropil, gliotic and perivascular lesions, and the pia matter in the cerebral cortex of both $\mathrm{AD}$ and non- $\mathrm{AD}$ cases, although the staining was more intense in AD brains (Fig. 2b; Supplementary Fig. 2). In all the cases, multipolar fibrillary astrocytes expressing an intense immunoreactivity for AQP4 were less prominently found,when compared with AQP1-expressing astrocytes. 
Fig. 1 Multipolar fibrillary astrocytes express AQP1 in the cerebral cortex of AD. The tissue sections of the motor cortex of AD patients were processed for double-labeling immunohistochemistry using a panel of antibodies listed in Table 1. a-c AQP1 (brown) and $\mathrm{A} \beta($ red $), \mathbf{d} \mathrm{AQP} 1$ (red) and GFAP (brown), e AQP1 (brown) and CD68 (red), and f AQP1 (brown) and factor VIII-related antigen (red). Multipolar fibrillary astrocytes expressing an intense AQP1 immunoreactivity are often located on the top of $\mathrm{A} \beta$ deposition (a)
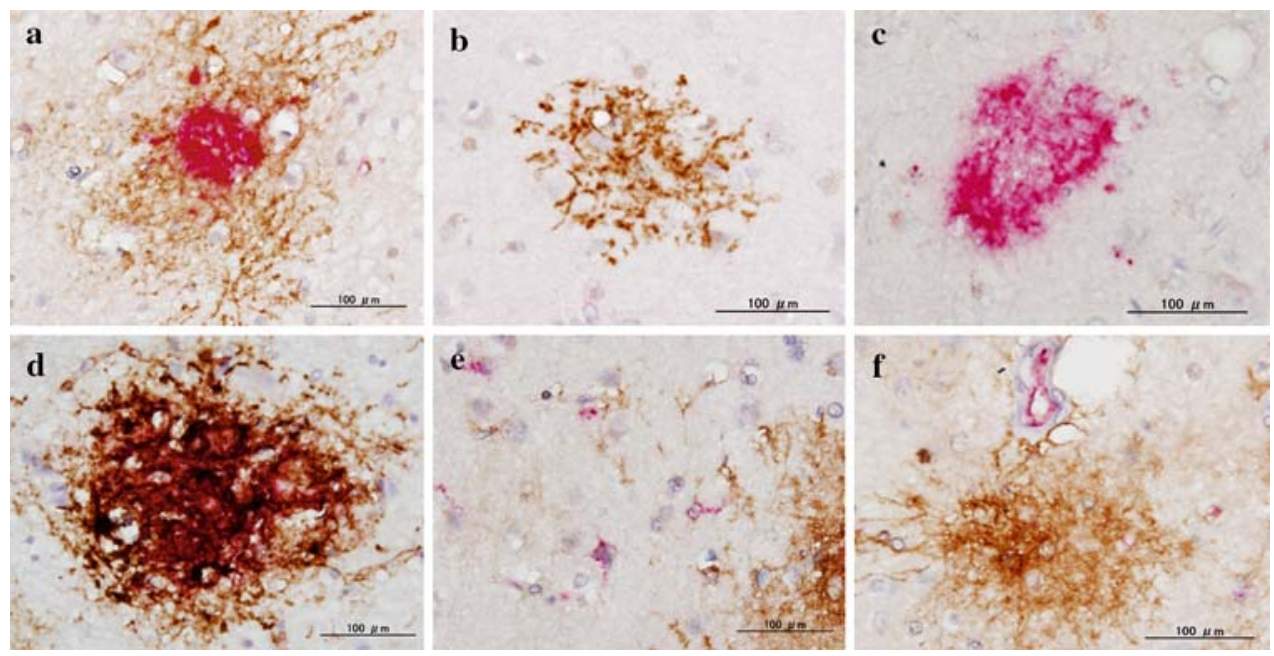
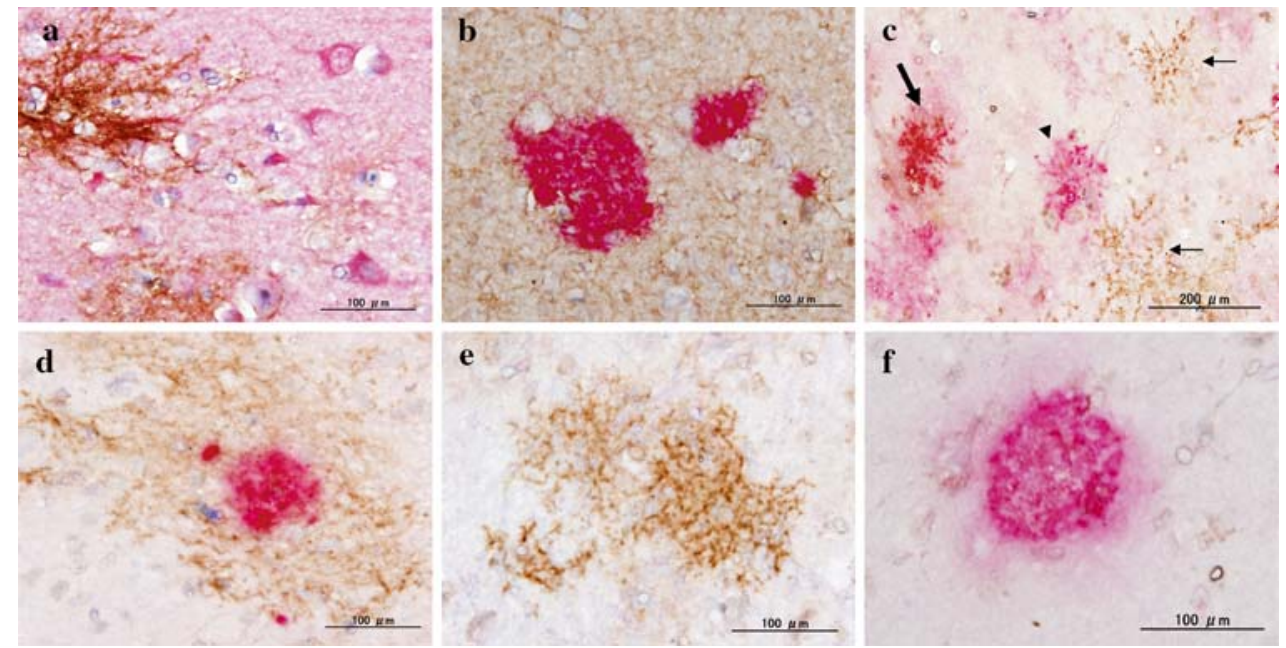

Fig. 2 Multipolar fibrillary astrocytes express AQP1 and AQP4 in the cerebral cortex of $\mathrm{AD}$ and other neurological diseases. The tissue sections of the motor cortex and the hippocampus of the patients with AD, Parkinson disease (PD), and amyotrophic lateral sclerosis (ALS) were processed for double-labeling immunohistochemistry using a panel of antibodies listed in Table 1. a the motor cortex of the patient with AD;

AQP1 (red) and NSE (brown), b the hippocampus of the patient with $\mathrm{AD}$; AQP4 (brown) and $\mathrm{A} \beta$ (red), $\mathbf{c}$ the hippocampus of the patient with ALS; AQP1 (red) and AQP4 (brown), and d-f the motor cortex of the patient with PD; AQP1 (brown) and A $\beta$ (red). Three distinct populations of astrocytes, $\mathrm{AQP} 1^{+} \mathrm{AQP} 4^{+}$(thick arrow), $\mathrm{AQP} 1^{+} \mathrm{AQP} 4^{-}$ (arrowhead), and $\mathrm{AQP} 1^{-} \mathrm{AQP} 4^{+}$(thin arrows), are identified (c)

Double labeling identified three distinct populations of astrocytes, $\mathrm{AQP} 1^{+} \mathrm{AQP} 4^{+}, \mathrm{AQP}^{+} \mathrm{AQP} 4^{-}$, and $\mathrm{AQP} 1^{-} \mathrm{AQP} 4^{+}$, suggesting that $\mathrm{AQP} 1$ and $\mathrm{AQP} 4$ might play an overlapping but non-redundant role in astrocytic water channel function (Fig. 2c). AQP1 $1^{+} \mathrm{AQP} 4^{+}$cells consisted of approximately $15 \%$ of all AQP-immunoreactive cells. Owing to the diffuse distribution of intense neuropil staining of AQP4, we could not clearly discriminate AQP4-immunoreactive astrocytes with or without a contact with $\mathrm{A} \beta$, making it highly difficult to count exactly the number of AQP4-expressing astrocytes located in the proximity to $\mathrm{A} \beta$ plaques.

Next, tissue sections of the motor cortex and hippocampus of $\mathrm{AD}$ and non- $\mathrm{AD}$ patients were processed for double-labeling immunohistochemistry with a combination of anti-AQP1 antibody and anti-A $\beta$ antibody. Then, we counted the number of $\mathrm{A} \beta^{+} \mathrm{AQP1} 1^{+}$plaques (Figs. $1 \mathrm{a}, 2 \mathrm{~d}$ ), $\mathrm{A} \beta^{-} \mathrm{AQP} 1^{+}$spots (Figs. $1 \mathrm{~b}, 2 \mathrm{e}$ ), and $\mathrm{A} \beta^{+} \mathrm{AQP} 1^{-}$plaques (Figs. 1c, 2f) with the size exceeding the diameter of $50 \mu \mathrm{m}$, by random scanning of the cerebral cortex at a $400 \times$ magnification under microscope (Fig. 3a, b). The average of percentages of $\mathrm{A} \beta^{+} \mathrm{AQP} 1^{+}$ plaques was significantly greater in both the motor cortex and hippocampus of $\mathrm{AD}$ than that of non- $\mathrm{AD}(P=1.092 \mathrm{E}-05$ in the motor cortex; $P=1.410 \mathrm{E}-05$ in the hippocampus). In contrast, the average of percentages of $\mathrm{A} \beta^{-} \mathrm{AQP} 1^{+}$spots was significantly greater in both the motor cortex and hippocampus of non-AD than that of $\mathrm{AD}(P=1.865 \mathrm{E}-05$ in the motor cortex; $P=5.035 \mathrm{E}-04$ in the hippocampus). By counting of ten random high magnification fields, the average of total 
(a) Motor cortex

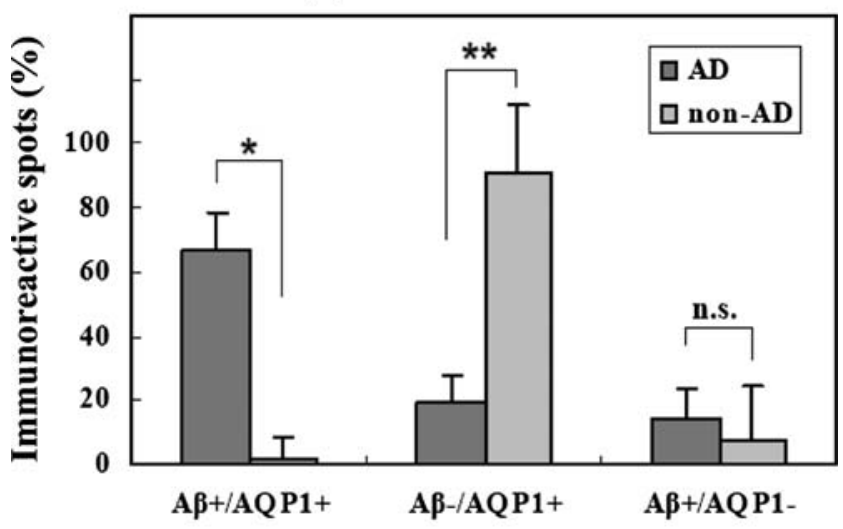

(b) Hippocampus

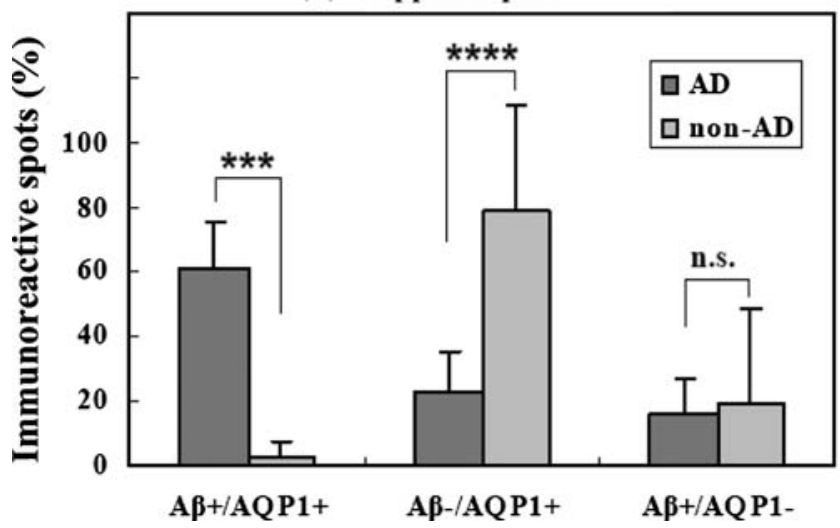

Fig. 3 The number of $\mathrm{AQP} 1$ and $\mathrm{A} \beta$-immunoreactive plaques in the cerebral cortex of AD. The tissue sections of the motor cortex and the hippocampus of $11 \mathrm{AD}$ patients and 16 age-matched non-AD patients were processed for double-labeling immunohistochemistry with antiAQP1 antibody $\mathrm{H}-55$ and anti-A $\beta$ antibody 12B2. The number of $\mathrm{A} \beta^{+} \mathrm{AQP} 1^{+}$plaques, $\mathrm{A} \beta^{+} \mathrm{AQP} 1^{-}$plaques, and $\mathrm{A} \beta^{-} \mathrm{AQP} 1^{+}$spots with the size exceeding the diameter of $50 \mu \mathrm{m}$ was counted by random scanning of the cerebral cortex at a $400 \times$ magnification under microscope. The percentage of immunoreactive plaques/spots, $\mathrm{A} \beta^{+} \mathrm{AQP} 1^{+}, \mathrm{A} \beta$ ${ }^{+} \mathrm{AQP} 1^{-}$or $\mathrm{A} \beta^{-} \mathrm{AQP} 1^{+}$, per the total was calculated, and the average is shown as the bar with standard deviation. a Motor cortex. b Hippocampus. $* P=1.092 \mathrm{E}-05, * * P=1.865 \mathrm{E}-05, * * * P=1.410 \mathrm{E}-05$, and $* * * * P=5.035 \mathrm{E}-04$

number of $\mathrm{A} \beta$-immunoreactive plaques or AQP1-immunoreactive plaques/spots larger than $50 \mu \mathrm{M}$ diameter was $16.2 \pm 4.7$ for $\mathrm{A} \beta$ and $16.3 \pm 4.4$ for $\mathrm{AQP} 1$ in the motor cortex of $\mathrm{AD}$, and $15.1 \pm 4.1$ for $\mathrm{A} \beta$ and $16.5 \pm 4.0$ for $\mathrm{AQP} 1$ in the hippocampus of $\mathrm{AD}$. In contrast, it was $0.6 \pm 1.9$ for $\mathrm{A} \beta$ and $2.7 \pm 1.8$ for AQP1 in the motor cortex of non-AD, and $2.6 \pm 4.5$ for $\mathrm{A} \beta$ and $8.6 \pm 6.1$ for $\mathrm{AQP1}$ in the hippocampus of non-AD. Thus, the average number of $\mathrm{A} \beta$-immunoreactive plaques and AQP1-immunoreactive plaques/ spots, was elevated significantly in the cerebral cortex of $\mathrm{AD}$ compared with non-AD $(P=1.217 \mathrm{E}-05$ for $\mathrm{A} \beta$ in the motor cortex; $P=6.416 \mathrm{E}-05$ for $\mathrm{A} \beta$ in the hippocampus; $P=1.092 \mathrm{E}-05$ for AQP1 in the motor cortex; and $P=0.003$ for AQP1 in the hippocampus). All of these observations suggest a close association of AQP1 with $\mathrm{A} \beta$ deposition in the cerebral cortex of AD. Alternatively, the possibility should be considered that the population of $\mathrm{A} \beta{ }^{+} \mathrm{AQP} 1^{+}$ plaques is much smaller in non- $\mathrm{AD}$ brains, because there existed less amounts of $\mathrm{A} \beta$ deposition and smaller numbers of AQP1-immunoreactive astrocytes in the brains of non-AD cases. In this setting, $\mathrm{A} \beta$ deposition might not be obligatory for induction of the astrocytic expression of AQP1.

The expression and induction of AQP1 in cultured human astrocytes

Since a subset of astrocytes intensely expressed AQP1 in $\mathrm{AD}$ and non-AD brains, in the next step, we investigated AQP1 expression in cultured human astrocytes. Consistent with high levels of AQP1 mRNA expression in cultured human astrocytes, as we reported previously [47], virtually all of them expressed constitutively a discernible immunoreactivity for AQP1, located mostly on the plasma membrane and less abundantly in the cytoplasm (Fig. 4a-d). The expression of AQP1 in astrocytes was further validated by Western blot. Cultured human astrocytes expressed constitutively a substantial amount of AQP1 protein with a molecular weight of $28-\mathrm{kDa}$, which represents the nonglycosylated form (Fig. 5a, lanes 1, 4, 6). They did not consistently express the glycosylated form with a larger molecular weight (data not shown). Then, cultured human astrocytes were exposed for $48 \mathrm{~h}$ to various stimuli that potentially affect the levels of AQP1 expression. The levels of AQP1 protein expression were not affected by treatment with either $\mathrm{A} \beta_{1-42}$ or $\mathrm{A} \beta_{1-40}$ peptide, but elevated markedly by exposure to $100 \mathrm{mM} \mathrm{NaCl}$, modestly by $10 \mu \mathrm{M}$ MG132 , and reduced substantially by treatment with $100 \mathrm{nM}$ phorbol 12-myristate 13-acetate (PMA) (Fig. 5, panel a, lanes $2,3,5,10,12)$. Upregulation by $\mathrm{NaCl}$ and downregulation by PMA were verified by real-time RT-PCR analysis (Supplementary Fig. 3). In contrast, the treatment with either sodium nitroprusside (SNP), hydrogen peroxide, retinoic acid (RA), dibutyryl cyclic AMP (dbcAMP), or thapsigargin (TG) did not affect the levels of AQP1 protein expression (Fig. 5 lanes 7, 8, 9, 11, 13). These results suggest that human astrocytes that express substantial amounts of AQP1 protein under the baseline culture condition are fairly resistant to induction of AQP1 by non-osmotic stimuli.

\section{Molecular interaction of AQP1 and CTF $\beta$ of APP}

Finally, the molecular interaction between AQP1 and A $\beta$ was investigated by immunprecipitation of recombinant fusion proteins with distinct epitope tags coexpressed in HEK293 cells, followed by pull down with tag-specific antibodies. Since preliminary experiments suggested that the segment spanning $\mathrm{A} \beta_{1-42}$ alone is not enough to identify 
Fig. 4 Cultured human astrocytes express AQP1 immunoreactivity. Cultured human astrocytes were processed for triple-labeling immunocytochemistry with anti-AQP1 antibody H-55, anti-GFAP antibody GA5, and DAPI. a AQP1, lower magnification; b AQP1, higher magnification; c GFAP, and $\mathbf{d}$ merge of $\mathbf{b}$ and $\mathbf{c}$ with DAPI
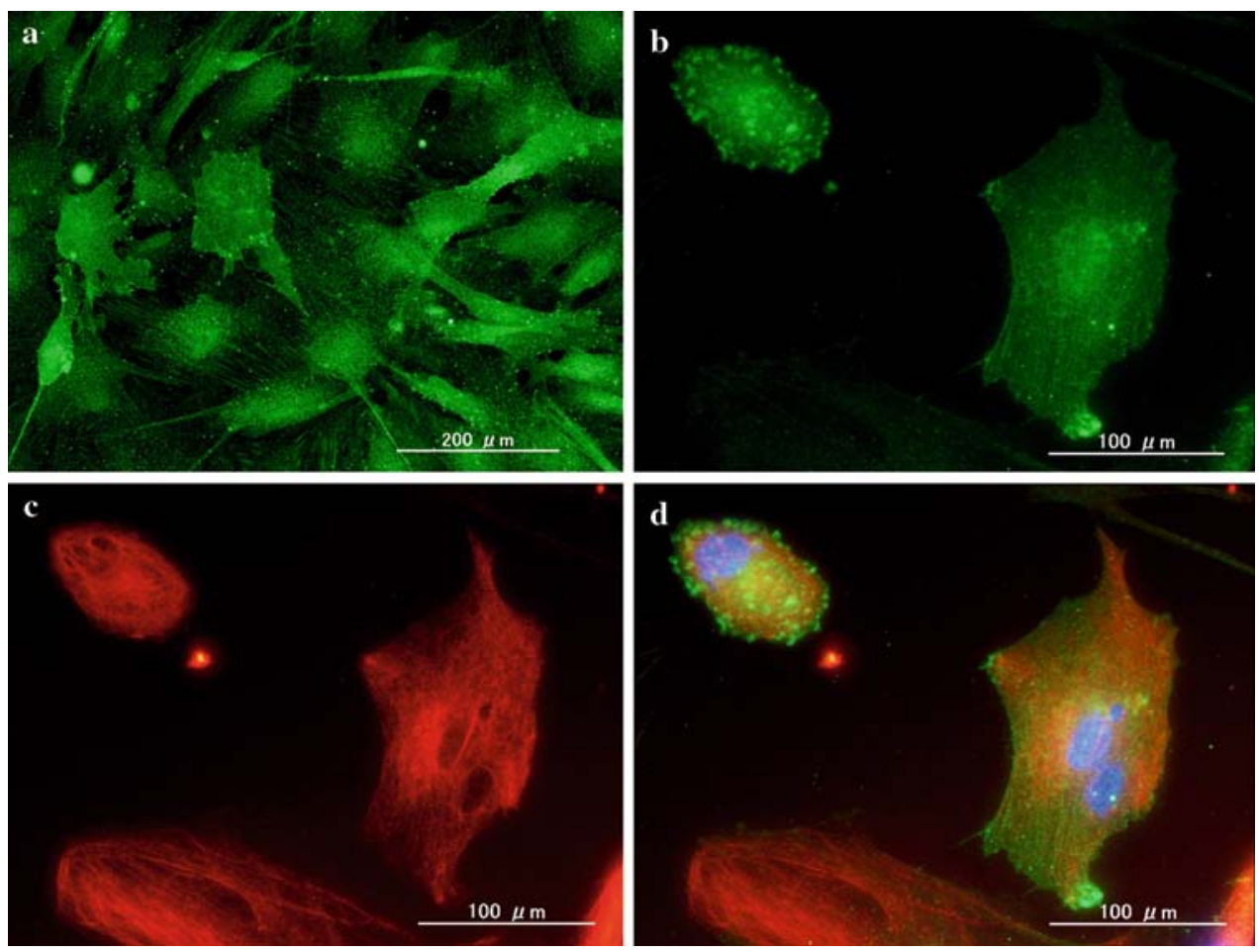

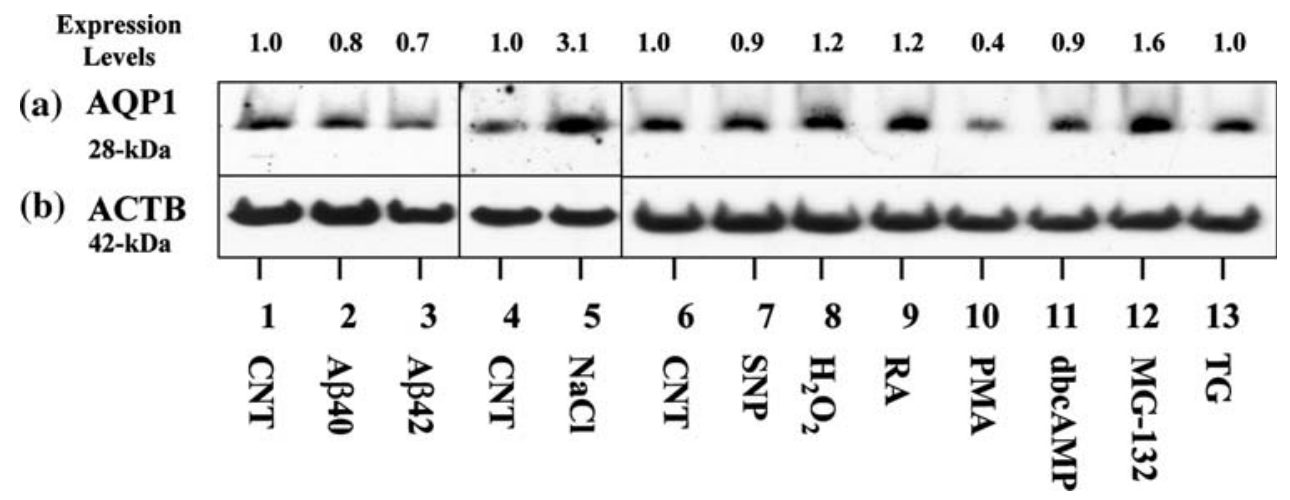

Fig. $5 \mathrm{AQP} 1$ protein levels in cultured human astrocytes exposed to various stimuli. Cultured human astrocytes were exposed for $48 \mathrm{~h}$ to the stimuli, and then processed for Western blot analysis with antiAQP1 antibody H-55. The identical blot was relabeled with anti- $\beta$ actin antibody AC-15. The panels consist of three distinct sets of experiments, composed of the set \#1 (lanes 1-3), the set \#2 (lanes 4 and 5), and the set \#3 (lanes 6-13). The lanes $(1-13)$ represent $(1,4,6)$ untreated or vehicle-treated cells, (2) $10 \mu \mathrm{M} \mathrm{A} \beta_{1-40}$ peptide, (3) $10 \mu \mathrm{M}$

the protein-protein interaction owing to its small size (4 kDa) on a conventional Tris-glycine SDS-PAGE gel, we have chosen the CTF $\beta$ of APP, spanning both $\mathrm{A} \beta$ and the APP intracellular domain (AICD), expressed as a Flagtagged fusion protein. Alternatively, either the NTF or the CTF of AQP1 was expressed as a Myc-tagged fusion protein. Pull-down assay showed that the CTF $\beta$ of APP interacts with the NTF of AQP1, but not with the CTF of AQP1, indicating that the molecular interaction is not attributable
A $\beta_{1-42}$ peptide, (5) $100 \mathrm{mM} \mathrm{NaCl}$, (7) $100 \mu \mathrm{M}$ sodium nitroprusside, (8) $100 \mu \mathrm{M}$ hydrogen peroxide, (9) $10 \mu \mathrm{M}$ all trans retinoic acid, (10) $100 \mathrm{nM}$ phorbol 12-myristate 13-acetate, (11) $1 \mathrm{mM}$ dibutyryl cyclic AMP, (12) $10 \mu \mathrm{M}$ MG-132, and (13) $1 \mu \mathrm{M}$ thapsigargin. Twenty-five microgram of protein was loaded on each lane. The expression levels indicate the ratio of AQP1 protein level of treated cells versus untreated cells, which were standardized against $\beta$-actin protein level

to an artifact caused by overexpression in HEK293 cells (Fig. 6a, b, upper and lower panels; lane 2).

To obtain additional evidence to support the results of immunoprecipitation analysis, we conducted cell imaging analysis. Either the $\mathrm{CTF} \beta$ or $\mathrm{A} \beta_{1-42}$ was expressed as a DsRedtagged fusion protein, while the full-length AQP1 was expressed as a GFP-tagged fusion protein. The CTF $\beta$ of APP, as well as $\mathrm{A} \beta_{1-42}$, was located chiefly in the cytoplasm, while AQP1 was expressed mainly on the plasma membrane, and 


\section{(A) AQP1-NTF (B) AQP1-CTF}

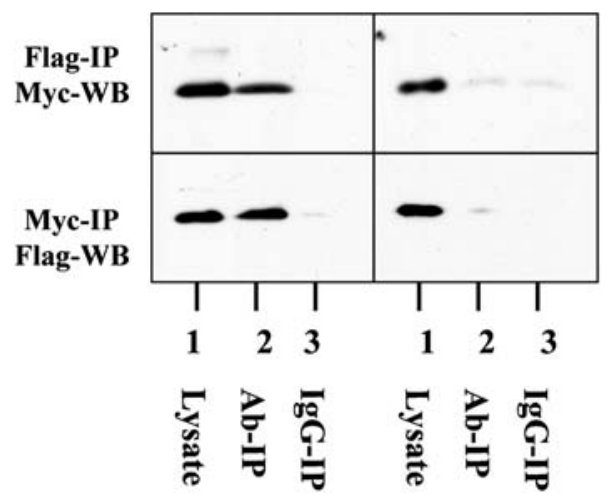

(C) Colocalization of AQP1 and A $\beta$
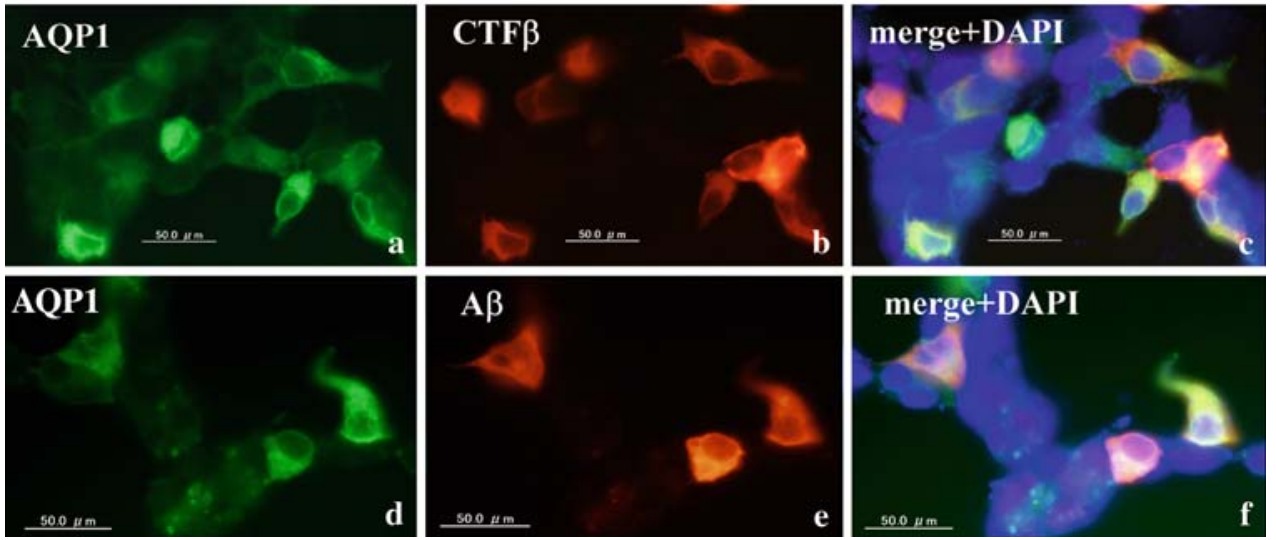

Fig. 6 Molecular interaction of AQP1 and the $\mathrm{CTF} \beta$ of APP. a, b Immunoprecipitation (IP) analysis. The C-terminal fragment-beta $(\mathrm{CTF} \beta)$ of amyloid precursor protein (APP) was expressed as a Flagtagged fusion protein, while either the NTF or the CTF of AQP1 was expressed as a Myc-tagged fusion protein. They were coexpressed in HEK293 cells, and processed for pull-down with anti-Flag or anti-Myc antibody, followed by Western blot reciprocally with anti-Myc or antiFlag antibody. a The interaction between CTF $\beta$ and NTF of AQP1. b The interaction between CFT $\beta$ and CTF of AQP1. The lanes (1-3) represent (1) input control of cell lysate, (2) IP with anti-tag antibodies, and (3) IP with normal mouse or rabbit IgG. c Cell imaging analysis. Either the $\mathrm{CTF} \beta$ or $\mathrm{A} \beta \beta_{-42}$ was expressed as a DsRed-tagged fusion protein, while the full-length AQP1 was expressed as a GFP-tagged fusion protein. They were coexpressed in HEK293 cells. $a$ AQP1 with a GFP fluorescence, $b \operatorname{CTF} \beta$ with a DsRed fluorescence, $c$ merge of $a$ and $b$ with DAPI, $d$ AQP1 with a GFP fluorescence, $e$ A $\beta_{1-42}$ with a DsRed fluorescence, and $f$ merge of $d$ and $e$ with DAPI

intensely with many neurons, neuropil, and microglia in AD brains, suggesting that these cells and constituents might express the molecules with AQP1-binding epitopes (Fig. 7b, panel a). The AQP1-Xpress probe did not label multipolar fibrillary astrocytes. In contrast, the LacZXpress probe did not react with neurons, microglia, astrocytes, or $\mathrm{A} \beta$ plaques, excluding non-specific interaction via the Xpress epitope of recombinant proteins (Fig. 7b, panel b).

\section{Discussion}

In the present study, we investigated the relationship between $\mathrm{A} \beta$ deposition and astrocytic AQP1 expression in the motor cortex and hippocampus of $11 \mathrm{AD}$ patients and 
(A)

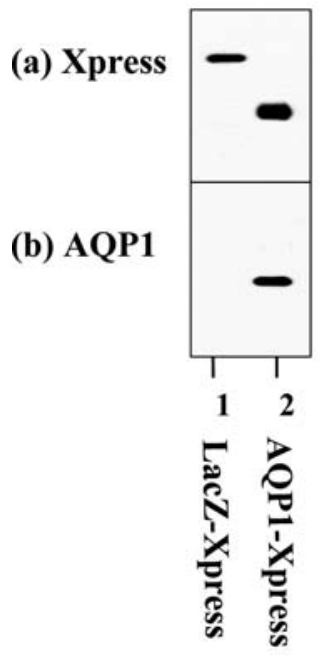

(B)

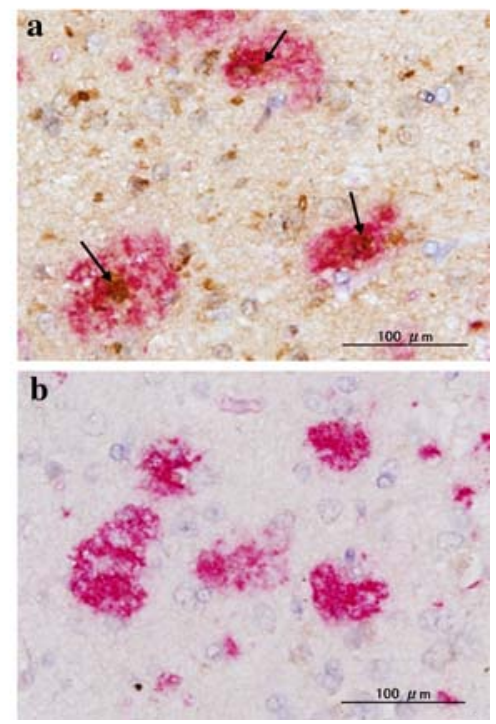

Fig. 7 Tissue protein overlay analysis with recombinant AQP1 protein as a probe. a Western blot of recombinant proteins. The identical blot was labeled sequentially with $a$ anti-Xpress antibody or $b$ antiAQP1 antibody H-55. b Tissue protein overlay. The tissue sections of the motor cortex of AD were incubated with $a \mathrm{AQP} 1-X p r e s s$ or $b$ LacZ-Xpress. Then, they were processed for immunolabeling with anti-Xpress antibody. After inactivation of the antibodies by autoclaving, the tissue sections were processed for relabeling with anti-A $\beta$ antibody. Xpress (brown) and $\mathrm{A} \beta$ (red). The arrows indicate an existence of AQP1-binding molecules in the core of $\mathrm{A} \beta$ deposition

16 age-matched non-AD cases. We found that AQP1 was expressed exclusively in a subpopulation of multipolar fibrillary astrocytes in all cases. The great majority of AQP1-expressing astrocytes were located either on the top of or in close proximity to $\mathrm{A} \beta$ plaques in $\mathrm{AD}$ brains but not in non-AD cases, whereas AQP1-expressing astrocytes independent of $\mathrm{A} \beta$ deposition were found predominantly in non-AD brains. By tissue protein overlay analysis, AQP1Xpress-immunoreactivities, reflecting the existence of the molecules with AQP1-binding epitopes, were located in the core of $\mathrm{A} \beta$ plaques in $\mathrm{AD}$ brains. A number of previous studies showed that astrocytes, keeping in touch with $\mathrm{A} \beta$ plaques, are activated by $\mathrm{A} \beta$ itself in $\mathrm{AD}$ brains $[37,55]$. In line with the previous observations, we showed that AQP1expressing multipolar fibrillary astrocytes are closely associated with $\mathrm{A} \beta$ deposition in $\mathrm{AD}$ brains. These observations suggest the hypothesis that $\mathrm{A} \beta$ deposition might cause abnormal brain water homeostasis by interfering with astrocytic water channel function. The present study included solely AD brains classified into the most advanced stage of the disease. To evaluate the hypothesis described above, it is important to investigate AQP1 expression in AD brains at early stages with minimal deposition or diffuse plaques of $\mathrm{A} \beta$. Importantly, a recent study using Western blot and immunohistochemistry showed that the levels of AQP1 protein expression are significantly elevated in the frontal cerebral cortex of AD at the Braak's stage II, where reactive astrocytes similar to multipolar fibrillary astrocytes observed in the present study express a cell-surface punctuate AQP1 immunoreactivity [43]. In contrast, no differences are found in AQP1 protein levels between the stages $\mathrm{V}-\mathrm{VI}$ of $\mathrm{AD}$ and the age-matched control cases, suggesting the possibility that upregulated expression of AQP1 on astrocytes in $\mathrm{AD}$ brains is a disease stage-dependent event [43].

To obtain a deeper insight into our in vivo observations of close association of AQP1-expressiong astrocytes with $\mathrm{A} \beta$, we studied the molecular interaction between AQP1 and $\mathrm{A} \beta$ in a transient expression system of HEK293 cells in vitro. By the pull-down assay, the CTF $\beta$ of APP interacts with the N-terminal half (amino acid residues 2-132; NTF) of AQP1 spanning the transmembrane helices $\mathrm{H} 1, \mathrm{H} 2$, and H3, which contains one of two NPA motifs pivotal for water transport function [2, 32]. A recent study indicated that the amino acid residues composed of Phe 58, His 182, Cys 191, and Arg 197 are involved in constituting the constriction region of water channel, while both His 76 and Val 155 act as a valve by dynamically blocking water permeation [49]. $\mathrm{AQP} 1$, along with the $\mathrm{CTF} \beta$ and $\mathrm{A} \beta_{1-42}$, were colocalized on the cell-surface membrane and in the cytoplasm, when they were coexpressed in cultured cells. Although the primary site of AQP1 expression is the cellsurface membrane, the intracellular location of AQP1 has been reported previously. AQP1 integrates into the ER membrane, when overexpressed in HEK293 cells [11]. Secretin induces a redistribution of AQP1 protein from intracellular vesicles to the plasma membrane in cholangiocytes [33]. Importantly, both APP and AQP1 constitute transmembrane proteins, and $\mathrm{A} \beta$ and $\mathrm{AQP} 1$ are enriched in lipid rafts of the plasma membrane [7, 52], raising the possibility of a direct protein-protein interaction between $\mathrm{A} \beta$ and AQP1 at cell-to-cell contact interfaces in situ.

However, it should be kept in mind that the binding of $\mathrm{AQP} 1$ to $\mathrm{A} \beta$ in vitro does not always precisely reflect the in vivo situation of the interaction between AQP1-expressing astrocytes and $\mathrm{A} \beta$. Importantly, both reactive astrocytes and activated microglia express scavenger receptors that mediate the clearance of extracellularly-deposited fibrillar $\mathrm{A} \beta[1]$. Therefore, it is meaningful to study in the next step the molecular interaction of $\mathrm{AQP} 1$ and fibrillar $\mathrm{A} \beta$, and its physiological interference with water transport in an astrocyte culture model in vitro. Although the present study, in the absence of high-resolution immunoelectron microscopic analysis dose not provide definitive evidence to show the direct interaction between $\mathrm{A} \beta$ and $\mathrm{AQP} 1$ in vivo, we could currently propose two different working models of the molecular interaction of AQP1 and A $\beta ;(1)$ astrocytic AQP1 could interact with extracellular deposition of 
fibrillary $\mathrm{A} \beta$ (Fig. 8a) and (2) astrocytic AQP1 could interact with the $\mathrm{A} \beta$ and/or AICD transmembrane/intracellular segment of endogenous APP (Fig. 8b).

Regulatory mechanisms underlying AQP1 expression are highly complex. Systemic hyponatremia elevates the levels of expression of AQP1 on choroid plexus epithelial cells [35]. Thyroid transcription factor-1 (TTF1), expressed in choroids plexus epithelium, facilitates CSF production by enhancing AQP1 gene expression [25]. Hypertonic stress induces the expression of AQP1 in rodent renal medullary cells by activating extracellular signal-regulated kinase (ERK), p38 MAP kinase, and c-Jun N-terminal kinase (JNK), all of which regulate a hypertonicity-responsive element (HRE) located in the AQP1 promoter [53]. Acetazolamide inhibits the osmotic water permeability by reducing AQP1 protein expression [56]. Treatment with corticosteroids increases the levels of AQP1 protein expression in the capillary endothelium of the peritoneal membrane and the lung $[26,50]$. AQP1 expression is induced in rat gliosarcoma cells by exposure to hypoxia, dexamethasone, and PDGF, and by incubating the cells in hypertonic culture media containing $\mathrm{NaCl}$, D-glucose or fructose [17].
Treatment with proteasome inhibitors elevates the levels of AQP1 protein expression in mouse fibroblasts [29]. All of these observations suggest that distinct promoter elements are activated in response to osmotic and non-osmotic stimuli in different cell types. We found that AQP1 expression in cultured human astrocytes is upregulated markedly by hypertonic sodium chloride, modestly by MG-132, and downregulated by PMA, an activator of protein kinase $\mathrm{C}$ (PKC). It is worthy to note that tetradecanoylphorbol 13acetate (TPA), another activator of PKC, induces a rapid decrease in AQP4 mRNA in rat astrocytes in culture [38].

The pathophysiological role of AQP1-expressing multipolar fibrillary astrocytes in AD brains remains unknown. Increasing evidence indicate that AQP1 acts as a gas transporter, such as $\mathrm{O}_{2}, \mathrm{CO}_{2}$, and $\mathrm{NO}[6,13,18]$. AQP1, by transporting $\mathrm{NO}$ out of endothelial cells and into vascular smooth muscle cells, plays a pivotal role in endotheliumdependent vasorelaxation [18]. AQP1 expression is markedly upregulated in rat lungs by hypoxia [13]. AQP1 is required for hypoxia-inducible angiogenesis in human retinal vascular endothelial cells [23]. We showed previously that AQP1-expressing astrocytes accumulate in ischemic
Fig. 8 Working models of the molecular interaction between AQP1 and A $\beta$. AQP1 is composed of a homotetramer of 28 $\mathrm{kDa}$ subunits. Each monomeric subunit contains six transmembrane helices (H1-H6) with two hemipores with an AsparagineProline-Alanine (NPA) motif, which fold to form a water channel (see the reference [32]). Pulldown assay suggested that the CTF $\beta$ of APP, composed of $\mathrm{A} \beta$ and AICD, interacts with the $\mathrm{N}$-terminal half of AQP1 spanning $\mathrm{H} 1, \mathrm{H} 2$, and $\mathrm{H} 3$. Two different working models could be proposed for the molecular interaction of AQP1 and $\mathrm{A} \beta$; $\mathbf{a}$ astrocytic AQP1 could interact with extracellular deposition of fibrillary $\mathbf{A} \beta$, and $\mathbf{b}$ astrocytic AQP1 could interact with the $\mathrm{A} \beta$ and/or AICD transmembrane/ intracellular segment of endogenous APP (a)
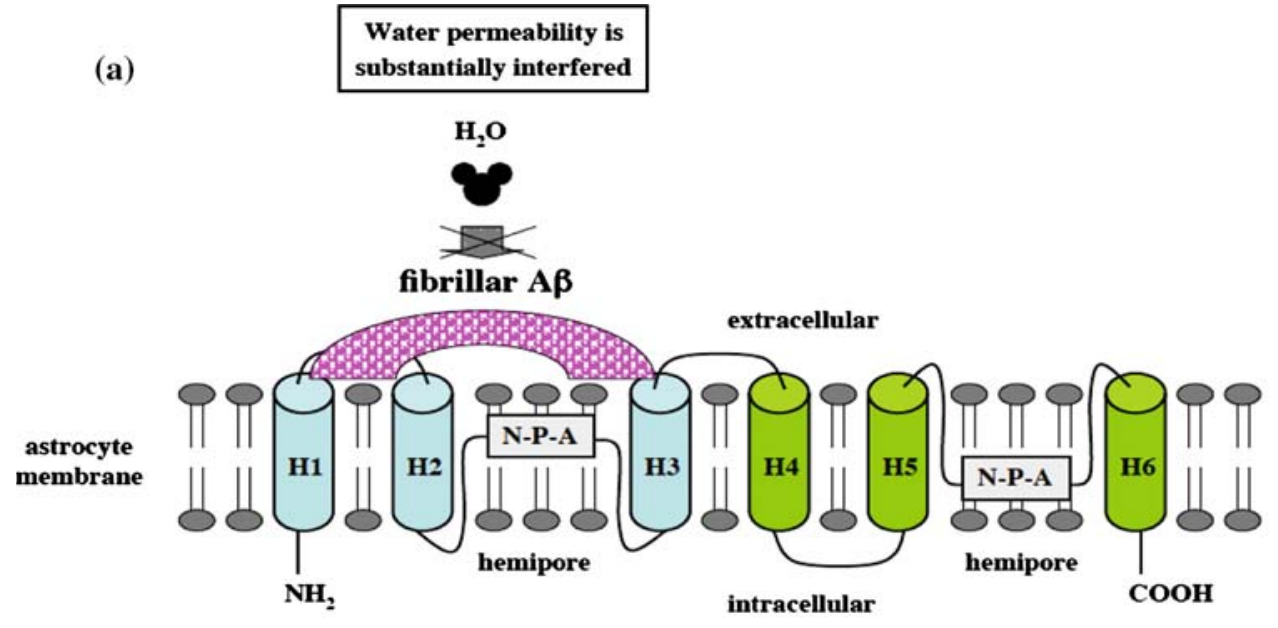

(b)

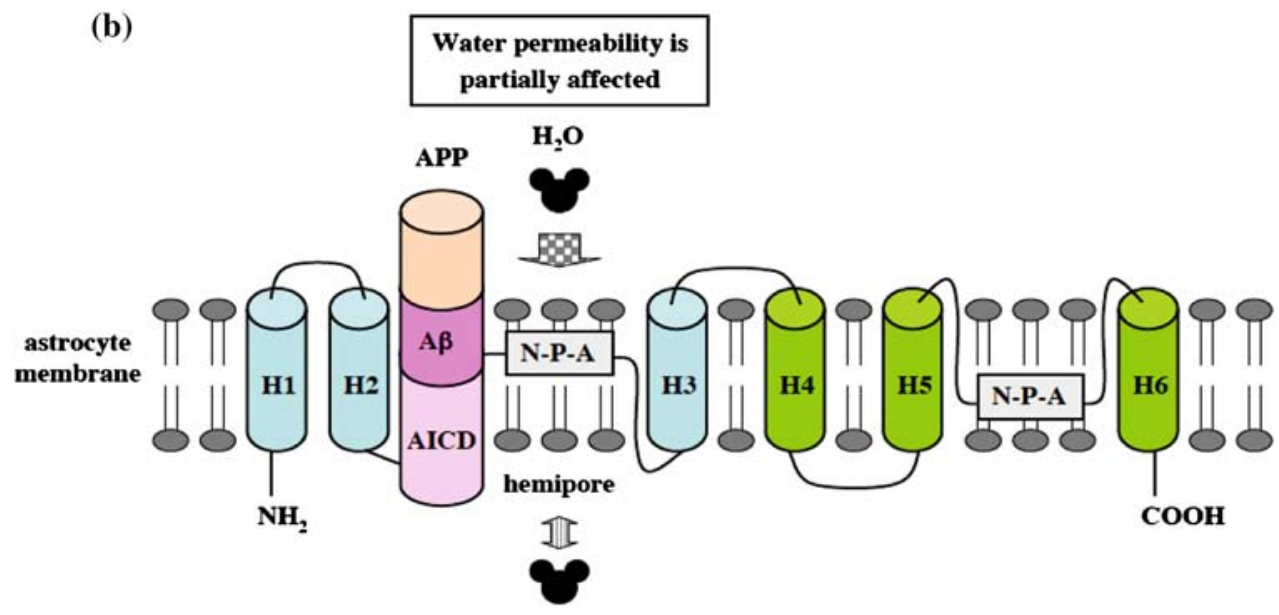


lesions of cerebral infarction and active demyelinating lesions of MS [47]. Because the production of NO and reactive nitrogen species (RNS), as well as reactive oxygen species (ROS), is markedly enhanced in the brains of ischemia, MS and AD [3], the possibility exists that AQP1expressing astrocytes with a great migratory capacity [54] act as a scavenger of RNS and ROS by patrolling the cortex of AD. However, treatment with SNP and hydrogen peroxide did not affect the levels of AQP1 protein expression in human astrocytes in culture, suggesting that these stimuli do not directly upregulate AQP1 expression in astrocytes.

We found that the levels of AQP1 protein expression on cultured human astrocytes were not affected by exposure to $\mathrm{A} \beta_{1-42}$ peptide at least within a $48 \mathrm{~h}$-observation period, although we observed a drastic change in morphology of astrocytes, exhibiting the morphology with ruffled cell-surface membranes (Supplementary Fig. 4). The molecular basis for this change remains unknown. Even though $\mathrm{A} \beta$ desposition does not act as a potent inducer for AQP1 expression in cortical astrocytes in AD brains, the close association of $\mathrm{AQP} 1$ with $\mathrm{A} \beta$ suggests that extensive $\mathrm{A} \beta$ deposition could cause abnormal brain water homeostasis by interfering with astrocytic water channel function. Supporting this view, previous clinical studies showed that brain ion and water homeostasis is profoundly disturbed in AD [5, 20]. Recent studies have indicated that intracerebral accumulation of not only $\mathrm{A} \beta$ oligomers but also that of the APP intracellular domain (AICD) affects the gene expression involved in neuronal survival [36]. Human astrocytes produce $\mathrm{A} \beta$ in response to TGF $\beta$, suggesting that astrocytes might coexpress $\mathrm{A} \beta$, along with AQP1, when activated by cytokines in AD brains [30]. The great majority of APP holoprotein is located in intracellular membranous compartments in cultured astrocytes [15]. AQP1 is produced initially as a precursor protein with four transmembrane segment-spanning topology at the ER membrane, and following topological reorientation it is processed to form a mature protein with six transmembrane segment-spanning topology at the plasma mambrane [31]. After overexpression of the transgenes without signal peptide sequences in HEK 293 cells, the CTF $\beta$ of APP, as well as that of $\mathrm{A} \beta_{1-42}$, was located chiefly in the cytoplasm, while AQP1 was expressed mainly on the plasma membrane and less abundantly in the cytoplasm. Although the overexpression experiments in HEK293 cells do not precisely reflect the physiological situation, a discernible colocalization was detected in the cytoplasm, not excluding the interaction in intracellular membranous compartments. The pull-down assay showed that the CTF $\beta$, composed of both $\mathrm{A} \beta$ and AICD, interacts directly with the NTF of AQP1, although these observations did not specify the AQP1-interacting domain of APP, either A $\beta$ or AICD, or both. Therefore, the possible scenario could be raised that astrocytic $\mathrm{A} \beta$ and/or
AICD segment of endogenous APP interacts with AQP1 either on the plasma membrane or at specific intracellular membrane compartments (Fig. 8b). In addition, the hypothetical view could be proposed that $\mathrm{A} \beta$ and $\mathrm{AICD}$, by binding to AQP1, not only affect water permeability, but also modulate signaling pathways in astrocytes essential for supporting neuronal survival in the brains of $\mathrm{AD}$.

In conclusion, AQP1-expressing fibrillary astrocytes, which represent a unique subset of astrocytes, might have a close association with $\mathrm{A} \beta$ in the brains of advanced stages of $\mathrm{AD}$, although there exists no definitive evidence to show the direct contact. However, these observations suggest the working hypothesis that $\mathrm{A} \beta$ deposition could cause abnormal brain water homeostasis by interfering with astrocytic water channel function. Further studies, including the immunohistochemical analysis of various disease stages, high-resolution morphological analysis, and cell physiological analysis, are required to evaluate this hypothesis.

Acknowledgments All autopsied brain samples were obtained from Research Resource Network (RRN), Japan. This work was supported by grants to JIS from Research on Psychiatric and Neurological Diseases and Mental Health, the Ministry of Health, Labour and Welfare of Japan (H17-kokoro-020), Research on Health Sciences Focusing on Drug Innovation, the Japan Health Sciences Foundation (KH21101), the Grant-in-Aid for Scientific Research, the Ministry of Education, Culture, Sports, Science and Technology, Japan (B18300118), and the Nakatomi Foundation.

Open Access This article is distributed under the terms of the Creative Commons Attribution Noncommercial License which permits any noncommercial use, distribution, and reproduction in any medium, provided the original author(s) and source are credited.

\section{References}

1. Alarcón R, Fuenzalida C, Santibáñez M, von Bernhardi R. (2005) Expression of scavenger receptors in glial cells. Comparing the adhesion of astrocytes and microglia from neonatal rats to surfacebound $\beta$-amyloid. J Biol Chem 280:30406-30415. doi:10.1074/ jbc.M414686200

2. Amiry-Moghaddam M, Ottersen OP (2003) The molecular basis of water transport in the brain. Nat Rev Neurosci 4:991-1001

3. Aslan M, Ozben T (2004) Reactive oxygen and nitrogen species in Alzheimer's disease. Curr Alzheimer Res 1:111-119. doi:10.2174/ 1567205043332162

4. Badaut J, Brunet JF, Grollimund L, Hamou MF, Magistretti PJ, Villemure JG, Regli L (2003) Aquaporin 1 and aquaporin 4 expression in human brain after subarachnoid hemorrhage and in peritumoral tissue. Acta Neurochir Suppl 86:495-498

5. Bartzokis G, Tishler TA (2000) MRI evaluation of basal ganglia ferritin iron and neurotoxicity in Alzheimer's and Huntingon's disease. Cell Mol Biol 46:821-833

6. Blank ME, Ehmke H (2003) Aquaporin-1 and HCO3-Cl- transporter-mediated transport of $\mathrm{CO} 2$ across the human erythrocyte membrane. J Physiol 550(Pt 2):419-429. doi:10.1113/jphysiol.2003.040113

7. Blonder J, Hale ML, Chan KC, Yu LR, Lucas DA, Conrads TP, Zhou M, Popoff MR, Issaq HJ, Stiles BG, Veenstra TD (2005) 
Quantitative profiling of the detergent-resistant membrane proteome of iota-b toxin induced vero cells. J Proteome Res 4:523-531. doi:10.1021/pr049790 s

8. Boassa D, Stamer WD, Yool AJ (2006) Ion channel function of aquaporin-1 natively expressed in choroid plexus. J Neurosci 26:7811-7819. doi:10.1523/JNEUROSCI.0525-06.2006

9. Braak H, Alafuzoff I, Arzberger T, Kretzschmar H, Del Tredici K (2006) Staging of Alzheimer disease-associated neurofibrillary pathology using paraffin sections and immunocytochemistry. Acta Neuropathol 112:389-404. doi:10.1007/s00401-006-0127-z

10. Buck TM, Wagner J, Grund S, Skach WR (2007) A novel tripartite motif involved in aquaporin topogenesis, monomer folding and tetramerization. Nat Struct Mol Biol 14:762-769. doi:10.1038/ nsmb1275

11. Dohke Y, Turner RJ (2002) Evidence that the transmembrane biogenesis of aquaporin 1 is cotranslational in intact mammalian cells. J Biol Chem 277:15215-15219. doi:10.1074/jbc.C100646200

12. Dolman D, Drndarski S, Abbott NJ, Rattray M (2005) Induction of aquaporin 1 but not aquaporin 4 messenger RNA in rat primary brain microvessel endothelial cells in culture. J Neurochem 93:825-833. doi:10.1111/j.1471-4159.2005.03111.x

13. Echevarría M, Muñoz-Cabello AM, Sánchez-Silva R, Toledo-Aral JJ, López-Barneo J (2007) Development of cytosolic hypoxia and hypoxia-inducible factor stabilization are facilitated by aquaporin1 expression. J Biol Chem 282:30207-30215. doi:10.1074/jbc. M702639200

14. Gao H, He C, Fang X, Hou X, Feng X, Yang H, Zhao X, Ma T (2006) Localization of aquaporin-1 water channel in glial cells of the human peripheral nervous system. Glia 53:783-787. doi:10.1002/ glia.20336

15. Haass C, Hung AY, Selkoe DJ (1991) Processing of $\beta$-amyloid precursor protein in microglia and astrocytes favors an internal localization over constitutive secretion. J Neurosci 11:37833793

16. Haass C, Selkoe DJ (2007) Soluble protein oligomers in neurodegeneration: lessons from the Alzheimer's amyloid $\beta$-peptide. Nat Rev Mol Cell Biol 8:101-112. doi:10.1038/nrm2101

17. Hayashi Y, Edwards NA, Proescholdt MA, Oldfield EH, Merrill MJ (2007) Regulation and function of aquaporin-1 in glioma cells. Neoplasia 9:777-787. doi:10.1593/neo.07454

18. Herrera M, Garvin JL (2007) Novel role of AQP-1 in NO-dependent vasorelaxation. Am J Physiol Renal Physiol 292:F1443F1451. doi:10.1152/ajprenal.00353.2006

19. Hoque MO, Soria JC, Woo J, Lee T, Lee J, Jang SJ, Upadhyay S, Trink B, Monitto C, Desmaze C, Mao L, Sidransky D, Moon C (2006) Aquaporin 1 is overexpressed in lung cancer and stimulates NIH-3T3 cell proliferation and anchorage-independent growth. Am J Pathol 168:1345-1353. doi:10.2353/ajpath.2006.050596

20. House MJ, St Pierre TG, Foster JK, Martins RN, Clarnette R (2006) Quantitative MR imaging R2 relaxometry in elderly participants reporting memory loss. AJNR Am J Neuroradiol 27:430-439

21. Hu J, Verkman AS (2006) Increased migration and metastatic potential of tumor cells expressing aquaporin water channels. FASEB J 20:1892-1894. doi:10.1096/fj.06-5930fje

22. Jablonski EM, Webb AN, McConnell NA, Riley MC, Hughes FM Jr (2004) Plasma membrane aquaporin activity can affect the rate of apoptosis but is inhibited after apoptotic volume decrease. Am J Physiol Cell Physiol 286:C975-C985. doi:10.1152/ajpcell.00180. 2003

23. Kaneko K, Yagui K, Tanaka A, Yoshihara K, Ishikawa K, Takahashi K, Bujo H, Sakurai K, Saito Y (2008) Aquaporin 1 is required for hypoxia-inducible angiogenesis in human retinal vascular endothelial cells. Microvasc Res 75(3):297-301. doi:10.1016/j. mvr.2007.12.003

24. Kang TH, Choi YK, Kim IB, Oh SJ, Chun MH (2005) Identification and characterization of an aquaporin 1 immunoreactive amacrine-type cell of the mouse retina. J Comp Neurol 488:352367. doi:10.1002/cne.20589

25. Kim JG, Son YJ, Yun CH, Kim YI, Nam-Goong IS, Park JH, Park SK, Ojeda SR, D'Elia AV, Damante G, Lee BJ (2007) Thyroid transcription factor-1 faciliattes cerebrospinal fluid formation by regulating aquaporin-1 synthesis in the brain. J Biol Chem 282:14923-14931. doi:10.1074/jbc.M701411200

26. King LS, Nielsen S, Agre P (1996) Aquaporin-1 water channel protein in lung. Ontogeny, steroid-induced expression, and distribution in rat. J Clin Invest 97:2183-2191. doi:10.1172/JCI118659

27. King LS, Choi M, Fernandez PC, Cartron JP, Agre P (2001) Defective urinary concentrating ability due to a complete deficiency of aquaporin-1. N Engl J Med 345:175-179. doi:10.1056/ NEJM200107193450304

28. King LS, Nielsen S, Agre P, Brown RH (2002) Decreased pulmonary vascular permeability in aquaporin-1-null humans. Proc Natl Acad Sci USA 99:1059-1063. doi:10.1073/pnas.022626499

29. Leitch V, Agre P, King LS (2001) Altered ubiquitination and stability of aquaporin-1 in hypertonic stress. Proc Natl Acad Sci USA 98:2894-2898. doi:10.1073/pnas.041616498

30. Lesné S, Docagne F, Gabriel C, Liot G, Lahiri DK, Buée L, Plawinski L, Delacourte A, MacKenzie ET, Buisson A, Vivien D (2003) Transforming growth factor- $\beta 1$ potentiates amyloid- $\beta$ generation in astrocytes and in transgenic mice. $\mathrm{J}$ Biol Chem 278:18408-18418. doi:10.1074/jbc.M300819200

31. Lu Y, Turnbull IR, Bragin A, Carveth K, Verkman AS, Skach WR (2000) Reorientation of aquaporin-1 topology during maturation in the endoplasmic reticulum. Mol Biol Cell 11:2973-2985

32. Magni F, Chinello C, Raimondo F, Mocarelli P, Kienle MG, Pitto M (2008) AQP1 expression analysis in human diseases: implications for proteomic characterization. Expert Rev Proteomics 5:2944. doi:10.1586/14789450.5.1.29

33. Marinelli RA, Pham L, Agre P, LaRusso NF (1997) Secretin promotes osmotic water transport in rat cholangiocytes by increasing aquaporin-1 water channels in plasma membrane. J Biol Chem 272:12984-12988. doi:10.1074/jbc.272.20.12984

34. Mirra SS, Heyman A, McKeel D, Sumi SM, Crain BJ, Brownlee LM, Vogel FS, Hughes JP, van Belle G, Berg L (1991) The consortium to establish a registry for Alzheimer's disease (CERAD). Part II. Standardization of the neuropathologic assessment of Alzheimer's disease. Neurology 41:479-486

35. Moon Y, Hong SJ, Shin D, Jung Y (2006) Increased aquaporin-1 expression in choroid plexus epithelium after systemic hyponatremia. Neurosci Lett 395:1-6. doi:10.1016/j.neulet.2005.10.060

36. Müller T, Concannon CG, Ward MW, Walsh CM, Tirniceriu AL, Tribl F, Kögel D, Prehn JH, Egensperger R (2007) Modulation of gene expression and cytoskeletal dynamics by the amyloid precursor protein intracellular domain (AICD). Mol Biol Cell 18:201210. doi:10.1091/mbc.E06-04-0283

37. Nagele RG, Wegiel J, Venkataraman V, Imaki H, Wang KC, Wegiel J (2004) Contribution of glial cells to the development of amyloid plaques in Alzheimer's disease. Neurobiol Aging 25:663-674. doi:10.1016/j.neurobiolaging.2004.01.007

38. Nakahama K, Nagano M, Fujioka A, Shinoda K, Sasaki H (1999) Effect of TPA on aquaporin 4 mRNA expression in cultured rat astrocytes. Glia 25:240-246. doi:10.1002/(SICI)1098-1136 (19990201)25:3<240::AID-GLIA4>3.0.CO;2-C

39. Nielsen S, Smith BL, Christensen EI, Agre P (1993) Distribution of the aquaporin CHIP in secretory and resorptive epithelia and capillary endothelia. Proc Natl Acad Sci USA 90:7275-7279. doi:10.1073/pnas.90.15.7275

40. Nishino T, Devuyst O (2007) Clinical application of aquaporin research: aquaporin-1 in the peritoneal membrane. Pflugers Arch. doi:10.1007/s00424-007-0402-4

41. Oshio K, Binder DK, Liang Y, Bollwn A, Feuerstein B, Berger MS, Manley GT (2005) Expression of the aquaporin-1 water 
channel in human glial tumors. Neurosurgery 56:375-381. doi:10.1227/01.NEU.0000148904.57841.6B

42. Oshio K, Watanabe H, Song Y, Verkman AS, Manley GT (2005) Reduced cerebrospinal fluid production and intracranial pressure in mice lacking choroid plexus water channel Aquaporin-1. FASEB J 19:76-78

43. Pérez E, Barrachina M, Rodríguez A, Torrejón-Escribano B, Boada M, Hernández I, Sánchez M, Ferrer I (2007) Aquaporin expression in the cerebral cortex is increased at early stages of Alzheimer disease. Brain Res 1128:164-174. doi:10.1016/j.brainres. 2006.09.109

44. Rodríguez A, Pérez-Gracia E, Espinosa JC, Pumarola M, Torres JM, Ferrer I (2006) Increased expression of water channel aquaporin 1 and aquaporin 4 in Creutzfeldt-Jakob disease and in bovine spongiform encephalopathy-infected bovine-PrP transgenic mice. Acta Neuropathol 112:573-585. doi:10.1007/s00401-006-0117-1

45. Saadoun S, Papadopoulos MC, Davies DC, Bell BA, Krishna S (2002) Increased aquaporin 1 water channel expression in human brain tumours. Br J Cancer 87:621-637. doi:10.1038/sj.bjc.6600512

46. Saadoun S, Papadopoulos MC, Hara-Chikuma M, Verkman AS (2005) Impairment of angiogenesis and cell migration by targeted aquaporin-1 gene disruption. Nature 434:786-792. doi:10.1038/ nature 03460

47. Satoh J, Tabunoki H, Yamamura T, Arima K, Konno H (2007) Human astrocytes express aquaporin- 1 and aquaporin- 4 in vitro and in vivo. Neuropathology 27:245-256. doi:10.1111/j.1440-1789. 2007.00774. $\mathrm{x}$

48. Shields SD, Mazario J, Skinner K, Basbaum AI (2007) Anatomical and functional analysis of aquaporin 1, a water channel in primary afferent neurons. Pain 131:8-20. doi:10.1016/j.pain. 2006.11.018
49. Smolin N, Li B, Beck D, Daggett V (2008) Side-chain dynamics are critical for water permeation through aquaporin-1. Biophys $\mathrm{J}$. doi:10.1529/biophysj.107.125187

50. Stoenoiu MS, Ni J, Verkaeren C, Debaix H, Jonas JC, Lameire N, Verbavatz JM, Devuyst O (2003) Corticosteroids induce expression of aquaporin-1 and increase transcellular water transport in rat epithelium. J Am Soc Nephrol 14:555-565. doi:10.1097/01.ASN. $0000053420.37216 .9 \mathrm{E}$

51. Suzuki R, Okuda M, Asai J, Nagashima G, Itokawa H, Matsunaga A, Fujimoto T, Suzuki T (2006) Astrocytes co-express aquaporin$1,-4$, and vascular endothelial growth factor in brain edema tissue associated with brain contusion. Acta Neurochir Suppl 96:398401

52. Taylor DR, Hooper NM (2007) Role of lipid rafts in the processing of the pathogenic prion and Alzheimer's amyloid-beta proteins. Semin Cell Dev Biol 18:638-648. doi:10.1016/j.semcdb.2007. 07.008

53. Umenishi F, Schrier RW (2003) Hypertonicity-induced aquaporin-1 (AQP1) expression is mediated by the activation of MAPK pathways and hypertonicity-responsive element in the AQP1 gene. J Biol Chem 278:15765-15770. doi:10.1074/jbc.M209980200

54. Verkman AS (2005) More than just water channels: unexpected cellular roles of aquaporins. J Cell Sci 118:3225-3232. doi:10.1242/ jes.02519

55. Wisniewski HM, Wegiel J (1991) Spatial relationships between astrocytes and classical plaque components. Neurobiol Aging 12:593-600. doi:10.1016/0197-4580(91)90091-W

56. Xiang Y, Ma B, Tao LI, Gao JW, Yu HM, Li XJ (2004) Acetazolamide inhibits aquaporin-1 protein expression and angiogenesis. Acta Pharmacol Sin 25:812-816 